\title{
Supplementation with Brazil nuts and green tea extract regulates targeted biomarkers related to colorectal cancer risk in humans
}

\author{
Ying $\mathrm{Hu}^{1}{ }^{*}$, Graeme H. McIntosh ${ }^{1}$, Richard K. Le Leu ${ }^{1}$, Roshini Somashekar ${ }^{1}$, Xing Q. Meng ${ }^{2}$, \\ Geetha Gopalsamy ${ }^{1}$, Libby Bambaca ${ }^{1}$, Ross A. McKinnon ${ }^{1}$ and Graeme P. Young ${ }^{1}$ \\ ${ }^{1}$ Flinders Centre for Innovation in Cancer, Flinders University, Adelaide, South Australia, Australia \\ ${ }^{2}$ Flinders Centre for Epidemiology and Biostatistics, School of Medicine, Flinders University, Adelaide, South Australia, \\ Australia \\ (Submitted 26 July 2016 - Final revision received 29 September 2016 - Accepted 13 October 2016 - First published online 7 December 2016)
}

\section{Abstract}

Se and green tea have been shown in epidemiological, observational and preclinical studies to be inversely related to the risk of developing colorectal cancer (CRC). However, there are limited studies to evaluate their regulatory effects on genes/proteins that relate to CRC oncogenesis in human subjects, such as selenoproteins, WNT signalling pathway, inflammation and methylation. This study examined the effects of supplementation of Se using Brazil nuts and green tea extract (GTE) capsules, alone and in combination, on targeted biomarkers. In total, thirty-two volunteers ( $>50$ years of age) with plasma Se $\leq 1.36 \mu \mathrm{mol} / 1$ were randomised to one of three treatment groups: nine to Se (approximately $48 \mu \mathrm{g} / \mathrm{d}$ ) as six Brazil nuts, eleven to four GTE capsules ( $800 \mathrm{mg}$ (-)-epigallocatechin-3-gallate) and twelve to a combination of Brazil nuts and GTE. Blood and rectal biopsies were obtained before and after each intervention. Plasma Se levels, rectal selenoprotein P (SePP) and $\beta$-catenin mRNA increased significantly in subjects consuming Brazil nuts alone or in combination, whereas rectal DNA methyltransferase (DNMT1) and NF- $\kappa$ B mRNA were reduced significantly in subjects consuming GTE alone or in combination. None of the interventions significantly affected rectal acetylated histone H3 or Ki-67 expression at the protein level or plasma C-reactive protein. Effects of the combination of Brazil nuts and GTE did not differ from what would be expected from either agent alone. In conclusion, supplementation of Brazil nuts and/or GTE regulates targeted biomarkers related to CRC oncogenesis, specifically genes associated with selenoproteins (SePP), WNT signalling ( $\beta$-catenin), inflammation (NF- $\kappa \mathrm{B}$ ) and methylation (DNMT1). Their combination does not appear to provide additional effects compared with either agent alone.

\section{Key words: Brazil nuts: Selenium: Green tea extract: Biomarkers: Colorectal cancer risk}

Colorectal cancer (CRC) is a major health problem worldwide with environmental factors such as diet and lifestyle being major risk factors of CRC. Increasing efforts have been made to prevent $\mathrm{CRC}$, including surveillance for early detection of adenomas, identifying biomarkers of CRC risk and developing chemopreventive agents, in the hope of reversing, inhibiting or halting further progression to cancer.

Pharmaceutical approaches with non-steroidal anti-inflammatory drugs (NSAID) including aspirin have been shown to be effective in CRC prevention, but the side-effects associated with these drugs are a concern ${ }^{(1,2)}$. There is a lot of interest in naturally occurring substances found in food for CRC prevention $^{(3)}$; two such agents of interest are Se, an essential trace micronutrient, and green tea, the second most widely consumed beverage in the world next to water ${ }^{(4)}$. Epidemiological and observational studies have identified the association between Se and/or green tea supplementation with risk of $\mathrm{CRC}^{(5-8)}$. Although preclinical studies have shown promising results in this regard, a few studies on Se or green tea have demonstrated their effectiveness as cancer preventive agents in human clinical trials ${ }^{(7,9)}$. A higher Se intake has been associated with reduced risk of colonic adenoma recurrence ${ }^{(7,10)}$; however, a large Se and Vitamin E Cancer Prevention Trial failed to show that Se affects prostate cancer risk ${ }^{(11)}$. A total of 10 cups of green tea daily was found to reduce recurrence of colorectal adenomas in polypectomy patients by $51.6 \%$ (from 31 to $15 \%)^{(12)}$, but the efficacy of green tea in human trials has not been consistently demonstrated ${ }^{(13)}$.

Dietary agents generally have a favourable safety profile, with good accessibility, low costs and strong biological plausibility, although they often have less potency compared with pharmaceutical compounds ${ }^{(14)}$. There is a growing interest for improving efficacy of cancer prevention by combination of dietary agents with complementary mechanisms ${ }^{(5)}$. The Linxian Chinese Cancer Prevention Trial (targeting 29584 adults) showed that a combination of $\beta$-carotene, vitamin $\mathrm{E}$ and $\mathrm{Se}$

Abbreviations: Ac-H3, acetylated histone H3; CRC, colorectal cancer; DNMT, DNA methyltransferase; EGCG, (-)-epigallocatechin-3-gallate; GTE, green tea extract; SePP, selenoprotein P.

* Corresponding author: Dr Y. Hu, fax +61 88204 3943, email ying.hu@flnders.edu.au 
resulted in a $9 \%$ significant reduction in total mortality, $13 \%$ in cancer mortality and $21 \%$ in gastric cancer mortality ${ }^{(15)}$. The combination of green tea catechins and NSAID also resulted in synergistic anticancer effect in both in vitro and in vivo experiments $^{(16)}$. Our previous study in the azoxymethaneinduced CRC animal model suggested that a combination of Se and green tea is more effective in suppressing colorectal oncogenesis than either Se or green tea alone. This protection is associated with regulation of genetic and epigenetic biomarkers implicated in the initiation and development of colonic carcinogenesis ${ }^{(17)}$. To date, no study has investigated the potential chemopreventive effects of a combination of Se and green tea on biomarkers relevant to CRC risk in human subjects.

The development of CRC is a process that often occurs over decades, and as a result the use of incidence and mortality end points in clinical trial is not always feasible given the cost and time frame. The progression of CRC involves disruptions of multiple signalling pathways and mechanisms. Therefore, it is crucial to identify molecular biomarkers in the cell signalling network that are altered during the process of CRC, but can be regulated by agents ${ }^{(18)}$. Using biomarkers can assess the effects of an agent across several biological levels (molecular and cellular) in interventional or preventive trials and might provide insights into the efficacy of an agent. Se has been shown to mediate its anti-cancer effect via increasing selenoprotein expression and acetylation of histone $\mathrm{H} 3$ (Ac-H3), reducing inflammation and WNT activation ${ }^{(19)}$. Se deficiency, genetic variation in the selenoprotein genes, inflammation, activation of WNT and NF- $\kappa \mathrm{B}$ pathways, reduced histone acetylation and overexpression of DNA methyltransferase 1 (DNMT1) are all implicated in increasing risk of $\mathrm{CRC}^{(20)}$. Green tea has anti-inflammatory effects, and may play a role in reducing WNT signalling and in inhibiting methylation of DNMT1 ${ }^{(13)}$.

The aim of the current study was to examine the potential effects of supplementation of Se using Brazil nuts and green tea extract (GTE) capsules alone and in combination on biomarkers related to the mechanism of action of these bioactive substances in human subjects.

\section{Methods}

\section{Subjects, recruitment and randomisation}

In total, sixty-one people aged $52-75$ years, considered at risk for CRC by virtue of their age, were recruited by advertisement for this open-label, parallel, randomised-controlled intervention study. Individuals with a plasma Se level exceeding $1.36 \mu \mathrm{mol} / 1$ $(108 \mu \mathrm{g} / \mathrm{l})$ were excluded to ensure that participants with a high background Se status were not included in the study. This level was just a bit higher than the median point of the Australian population $^{(21)}$. It has previously been shown that CRC risk is reduced in subjects with a baseline plasma Se of $>1 \cdot 3 \mu \mathrm{mol} / 1^{(22,23)}$. Exclusion criteria included evidence of active bowel disease (e.g. colitis or malabsorption), previous bowel surgery, previous adenoma removal, allergy or intolerance to nuts or green tea products and use of warfarin or antiplatelet agents (such as aspirin). In all, fifteen male and seventeen female healthy volunteers met criteria for randomisation.
Participants were randomly assigned to groups (1:1:1) via a computer-generated randomisation sequence. Allocation concealment was achieved by keeping codes in a sealed envelope by a person who was not in contact with study subjects, and codes were disclosed after the study. Participants were instructed to maintain their usual diet during the study but to avoid consuming green tea-related food or drinks (limited to $<3$ cups of black tea) and Se-rich foods such as octopus, crab and tuna, liver and kidney, or additional Brazil nuts and other nuts. It was impossible to blind participants because of the nature of the intervention (especially the Brazil nuts), but all data curation, checking, measurements and data analysis were conducted by researchers blinded to treatment allocation of subjects.

The study was approved by the Flinders Clinical Research Ethics Committee (reference no. 308/12; Flinders Medical Centre), and the trial registration number is ACTRN12613000097741. All volunteers provided their written informed consent for participation in the present study and for biopsies to be used exclusively for this study.

\section{Selenium supplement}

Brazil nuts (supplied by Charlesworth) were chosen for the study because they are one of the richest known food sources of bioavailable Se. We used six Brazil nuts for the intervention. The Se content of Brazil nuts was measured by SA Pathology; the average Se content of each Brazil nut was $2.7 \mu \mathrm{g} \mathrm{Se} / \mathrm{g}$, and the average weight of each nut was $3 \mathrm{~g}$, somewhat lower than that reported by Thomson et al. ${ }^{(24)}$, who reported average Se concentration and weight of $6.4 \mu \mathrm{g} \mathrm{Se} / \mathrm{g}$ and $4 \mathrm{~g}$, respectively. Thus, six Brazil nuts were required in this study to provide approximately $48 \mu \mathrm{g} \mathrm{Se} / \mathrm{d}$, a level close to that previously used $(50 \mu \mathrm{g} \mathrm{Se} / \mathrm{d})$ by Thomson et al. ${ }^{(24)}$.

\section{Green tea supplement}

GTE capsules were chosen because they are more convenient than drinking the volume of green tea needed to deliver the required dosage. GTE capsules were supplied by NOW Foods. A capsule of green tea contained $200 \mathrm{mg}$ of '(-)-epigallocatechin3-gallate' (EGCG), a key bioactive compound in green tea; four capsules contain $800 \mathrm{mg}$ EGCG, which is equivalent to 8-16 cups of green tea ${ }^{(25)}$. Previous studies have reported that intake of GTE containing $400 \mathrm{mg}$ EGCG up to $2000 \mathrm{mg}$ EGCG is safe in human trials ${ }^{(26)}$. Crew et al. ${ }^{(27)}$ observed that $1200 \mathrm{mg}$ EGCG/d could be used as the upper safety limit for future long-term human intervention trials.

\section{Study protocol}

Subjects were randomly assigned to a 6-week supplementation period, preceded by a run-in period of 4 weeks, with either Se in the form of Brazil nuts, GTE capsules or a combination of Brazil nuts and GTE. The intervention was pragmatic, and allowed participants to re-adjust the remainder of their diet as they desired. Of the thirty-two subjects who participated, thirty completed the study, nine consumed Brazil nuts ( $48 \mu \mathrm{g} \mathrm{Se} / \mathrm{d})$, 
ten consumed GTE (800 mg EGCG/d) and eleven consumed a combination of Brazil nuts ( $48 \mu \mathrm{g}$ Se/d) and GTE ( $800 \mathrm{mg}$ EGCG/d) for 6 weeks. Peripheral blood samples were collected at baseline (week 0) and at the end of the intervention (week 6). Four rectal biopsy samples were obtained at baseline and at the end of the intervention. Blood samples were used to measure change in plasma Se levels, markers of inflammation and glucose homoeostasis as well as markers for liver, renal and thyroid functions. Rectal biopsies were used to measure gene and protein expressions associated with selenoproteins, WNT signalling pathway, inflammation, histone acetylation, methylation and cell proliferation.

\section{Blood sampling and plasma selenium and biochemistry measurements}

Blood samples were collected according to a standardised protocol in 10-ml EDTA-coated tubes. Samples were centrifuged for $10 \mathrm{~min}(3000 \mathrm{~g})$ at $48^{\circ} \mathrm{C}$, and the plasma samples were stored at $-80^{\circ} \mathrm{C}$ until analysis. Blood biochemistry was measured by SA Pathology.

\section{Processing of biopsies}

Rectal biopsies were obtained at flexible sigmoidoscopy using biopsy forceps; two biopsy specimens were placed in RNAlater (Applied Biosystems/Ambion, Ambion, Inc.) solution at $-4^{\circ} \mathrm{C}$ for $24 \mathrm{~h}$ and then stored at $-80^{\circ} \mathrm{C}$ for rectal gene expression analysis, and two more biopsy specimens were formalin fixed and embedded in paraffin for immunohistochemical analysis.

\section{RNA isolation and complementary DNA synthesis}

Total RNA (approximately $30 \mathrm{mg}$ ) was extracted from rectal biopsy samples using the TRIzol method (Invitrogen). The concentration and purity of total RNA were estimated using a NanoDrop ND-1000 UV-Vis spectrophotometer (ThermoFisher Scientific). First-strand complementary DNA (cDNA) $(20 \mu \mathrm{l})$ was synthesised from $0.3 \mu \mathrm{g}$ total RNA for each sample using a QuantiTect Reverse Transcription Kit (Qiagen).

\section{Quantitative real-time RT-PCR}

PCR was performed in triplicate on a Rotor-Gene 3000 Cycler (Corbett). Oligonucleotide primers were designed using Primer Express software version 1.5 (Applied Biosystems) on the basis of sequences from the GeneBank data base (Table 1). The PCR reaction was determined in a $20-\mu \mathrm{l}$ final volume containing $6 \mu \mathrm{l}$ of diluted 1:30 cDNA and 2x QuantiTect SYBR Green PCR Kit (Qiagen). The primer concentration for each gene was $10 \mu \mathrm{M}$ (forward and reverse primer). The cycling protocol was similar to that described by us previously ${ }^{(28,29)}$. The specificity of PCR was confirmed by melting curve analysis of the amplified PCR products. For each PCR run, a non-template reaction was included as negative control.

Cycle thresholds were determined using the relative quantitation analysis module in Rotor-Gene 3000 Series software. The amplification efficiency of each primer pair was estimated from a real-time PCR dilution curve generated using serial dilutions of cDNA. Quantitative real-time PCR analysis was then performed using Q-Gene software ${ }^{(30)}$, with the amplification efficiency applied to the relative concentration analyses of both the genes of interest and the housekeeping gene ( $\beta$-actin). Gene of interest expression data were normalised by dividing by the corresponding levels of $\beta$-actin for each sample.

\section{Immunohistochemistry}

Immunohistochemistry (IHC) was carried out by staining formalin-fixed, paraffin-embedded, 4- $\mu$ m rectal biopsy samples with Ki-67 mouse monoclonal primary antibody (M7248; DakoCytomation) and Ac-H3 rabbit polyclonal primary antibody (H3 (Lys9/Lys14), no. 9677; Cell signalling). The detailed procedures for immunohistochemical analysis have been reported previously ${ }^{(31)}$. In brief, after antigen retrieval, sections were incubated with Ki-67 antibody (1:1000) and Ac-H3 antibody (1:5000) overnight after incubation in $3 \% \mathrm{H}_{2} \mathrm{O}_{2}$ for $20 \mathrm{~min}$. A level-2 Ultra Streptavidin detection system (Signet Laboratories, Inc.) was used to detect positive staining. Visualisation was performed using DAB chromogen (Covance Laboratories), followed by counter-staining with haematoxylin. The negative

Table 1. Oligonucleotide primers

\begin{tabular}{|c|c|c|c|c|}
\hline Gene & Gene accession no. & Primers & Primer sequence $5^{\prime}-3^{\prime}$ & Product size (bp) \\
\hline SePP & NM_005410 & $\begin{array}{l}\text { Sense } \\
\text { Antisense }\end{array}$ & $\begin{array}{l}\text { TTACTGTGAAAAGAAATGTGGAACTG } \\
\text { AAAGCTCACTGCTGCCAAGGG }\end{array}$ & 78 \\
\hline$\beta$-Catenin & X87838.1 & $\begin{array}{l}\text { Sense } \\
\text { Antisense }\end{array}$ & $\begin{array}{l}\text { TGGAATGCAAGCTTTAGGAC } \\
\text { GAAAGAATTCCAGCTGCACAG }\end{array}$ & 192 \\
\hline $\mathrm{NF}-\kappa \mathrm{B}$ & ENSG00000109320 & $\begin{array}{l}\text { Sense } \\
\text { Antisense }\end{array}$ & $\begin{array}{l}\text { CCTCCACAAGGCAGCAAATAG } \\
\text { CTGAGTTTGCGGAAGGATGTCT }\end{array}$ & 85 \\
\hline c-Myc & ENSG00000136997 & $\begin{array}{l}\text { Sense } \\
\text { Antisense }\end{array}$ & $\begin{array}{l}\text { CACCAGCAGCGACTCTGA } \\
\text { GATCCAGACTCTGACCTTTTGC }\end{array}$ & 102 \\
\hline Cyclin D1 & ENST00000535993 & $\begin{array}{l}\text { Sense } \\
\text { Antisense }\end{array}$ & $\begin{array}{l}\text { CACCAGCAGCGACTCTGA } \\
\text { ATTGGA AATGAA CTTCACATCTG }\end{array}$ & 161 \\
\hline DNMT1 & XM_017218 & $\begin{array}{l}\text { Sense } \\
\text { Antisense }\end{array}$ & $\begin{array}{l}\text { GCACCTCATTTGCCGAATACA } \\
\text { TCTCCTGCATCAGCCCAAATA }\end{array}$ & 75 \\
\hline$\beta$-Actin & NM_001101 & $\begin{array}{l}\text { Sense } \\
\text { Antisense }\end{array}$ & $\begin{array}{l}\text { TTCTACAATGAGCTGCGTGTG } \\
\text { ATAGCAACGTACATGGCTGG }\end{array}$ & 140 \\
\hline
\end{tabular}

SePP, selenoprotein P; DNMT1, DNA methyltransferase 1. 
control consisted of sections and reagents without the primary antibodies. Positive staining was identified by a reddish brown precipitate in the nucleus for Ki-67 and acetyl histone H3.

All sections were examined by an experienced observer, who was blinded to the intervention groups. The sections were evaluated by Leica DMLA light microscope (Microsystems). The IHC evaluation was made by counting Ki-67- and Ac-H3-stained cells; a total of ten random microscopic fields per sample (about total 1500-2000 cells) were selected from each subject and counted at $40 \times$ magnification as described previously by others $^{(32,33)}$. The proliferation and histone acetylation indices were calculated as the percentage of Ki-67- or Ac-H3-stained cells in ten visualised fields divided by the total number of epithelial cells in ten fields, reported as a mean proliferation index (\%) or a mean $\mathrm{Ac}-\mathrm{H} 3$ index (\%)

\section{Statistical analysis}

Stata software (version 14.1; StataCorp LP) was used for the analysis. Outcome variables were checked for normality by constructing a histogram and performing skewness and kurtosis tests. Descriptive statistics, mean values and standard deviation before (baseline) and after treatment, or mean values with their standard error mean for change between baseline and the end of treatment, were reported. Mixed-effect models were used to estimate the mean difference within group over time, as well as the difference in mean change between groups. Baseline value, age and sex were adjusted in all models. C-reactive protein (CRP) and thyroxine (T4) were highly right-skewed, and their log-transformed results are also reported. Statistical analyses were two-sided, and a $P$ value of $<0.05$ was considered to be statistically significant for within-group and between-group comparisons.

\section{Results}

\section{Subject characteristics and compliance}

A total of thirty-two participants met inclusion criteria and participated in the study. The participant flow diagram is illustrated in Fig. 1. Characteristics of subjects at recruitment are summarised in Table 2; there were no significant differences in the characteristics between treatment groups. Their mean age was 64 years, ranging from 52 to 76 years, and Se levels were $\leq 1.36 \mu \mathrm{mol} / 1$. Of thirty-two participants, thirty completed the intervention study (thirteen males and seventeen females). One participant withdrew after 1 week of GTE supplementation because of abdominal discomfort perceived to be due to the GTE, whereas the other from the combination group complained of a sore anus after sigmoidoscopy and was unwilling to continue the study. The remaining thirty participants tolerated both Brazil nuts and GTE. There was very good compliance among those completing the study as all participants consumed the provided Brazil nuts or GTE capsules, judged by counting the number of Brazil nuts and GTE capsules at the end of the supplementation period.

\section{Effect of intervention on blood biochemistry}

Plasma Se levels significantly increased by $22.5 \%$ from baseline in subjects consuming Brazil nuts (from 1.29 (SD 0.14) to 1.58 (sD $0 \cdot 18) \mu \mathrm{mol} / \mathrm{l}$ ) and by $19.3 \%$ in subjects consuming the combination of Brazil nuts and GTE (from 1.35 (SD 0.15) to 1.61 (sD 0.26) $\mu \mathrm{mol} / \mathrm{l}$ ), respectively, $P<0.001$ (Table 3). Plasma Se levels did not change in those consuming GTE only. There were no significant disturbances in plasma glucose or CRP in any of the participants. A significant fall in creatinine levels (from) (70.3 (SD 12.3) to 65.9 (SD 13.9) $\mu \mathrm{mol} / \mathrm{l}$ ) was observed in subjects

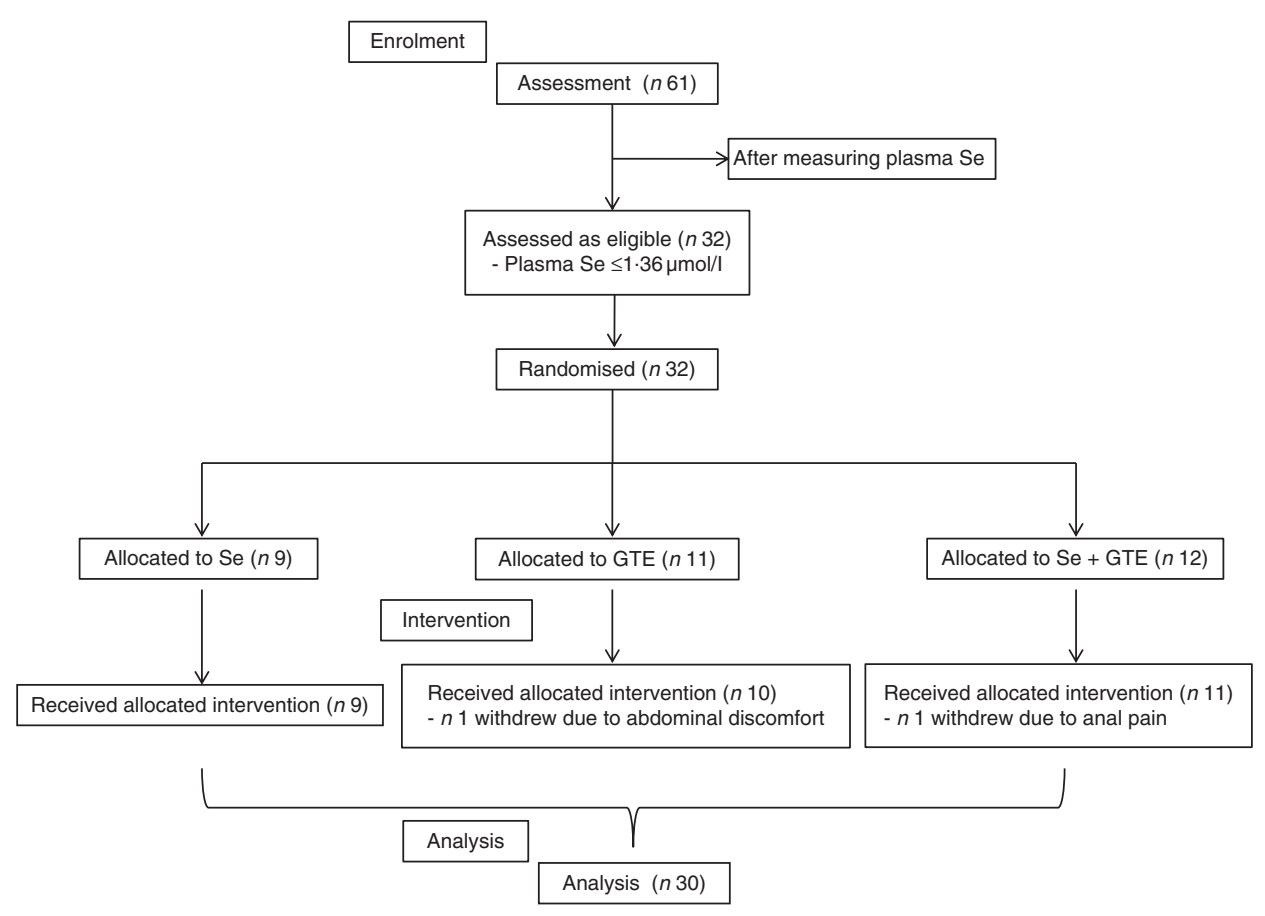

Fig. 1. CONSORT diagram of patient disposition. GTE, green tea extract. 
Table 2. Characteristics of subjects at recruitment

\begin{tabular}{|c|c|c|c|c|c|c|c|}
\hline & \multicolumn{2}{|c|}{ Brazil nuts (Se) } & \multicolumn{2}{|c|}{ GTE } & \multicolumn{2}{|c|}{$\mathrm{Se}+\mathrm{GTE}$} & \multirow[b]{2}{*}{$P$} \\
\hline & Mean & SD & Mean & SD & Mean & SD & \\
\hline No. of subjects & \multicolumn{2}{|c|}{9} & \multicolumn{2}{|c|}{11} & \multicolumn{2}{|c|}{12} & \\
\hline Male/female & \multicolumn{2}{|c|}{$5 / 4$} & \multicolumn{2}{|c|}{$5 / 6$} & \multicolumn{2}{|c|}{$5 / 7$} & \\
\hline Age (years) & $63 \cdot 3$ & 6.9 & $66 \cdot 5$ & 6.9 & 62.4 & $8 \cdot 8$ & NS \\
\hline Weight (kg) & 90.9 & $14 \cdot 2$ & 83.9 & $22 \cdot 4$ & $82 \cdot 2$ & $10 \cdot 8$ & NS \\
\hline Plasma Se $(\mu \mathrm{mol} / \mathrm{l})$ & 1.27 & 0.09 & 1.25 & 0.13 & 1.29 & 0.14 & NS \\
\hline
\end{tabular}

GTE, green tea extract; NS, no significant difference between the intervention groups.

consuming the combination of Brazil nuts and GTE, $P<0.001$ (Table 3). Urea level was significantly increased in subjects consuming Brazil nuts (from 6.0 (sD 1.5) to 6.6 (sD 1.4) mmol/1 after intervention), $P<0.005$. There was no significant difference in triiodothyronine (T3), T4 and thyroid-stimulating hormone levels between baseline and after intervention in any of the intervention groups.

\section{Effect of intervention on gene expression}

Changes in rectal gene expressions of selenoprotein $\mathrm{P}$ (SePP), DNMT1, $\beta$-catenin, c-Myc, cyclin D1 and NF- $\kappa$ B are shown in Fig. 2. At the end of the 6-week intervention, levels of SePP mRNA were significantly increased by 89 and $91 \%$, respectively, from baseline in subjects consuming Brazil nuts or consuming the combination of Brazil nuts and GTE, $P<0 \cdot 05$, but not in subjects consuming GTE alone. Expression of DNMT1 mRNA was significantly reduced from baseline by 30 and $35 \%$, respectively, in subjects consuming GTE or the combination of Brazil nuts and GTE, $P<0 \cdot 05$. NF- $\kappa \mathrm{B}$ mRNA was also significantly reduced from baseline by 44 and $46 \%$, respectively, in these two groups, $P<0 \cdot 05$, but DNMT1 and NF- $\kappa \mathrm{B}$ were unchanged in subjects consuming Brazil nuts. Significantly reduced expression of $\beta$-catenin was also observed in subjects consuming Brazil nuts or consuming the combination of Brazil nuts and GTE; the reduction in these two group was 28 and $40 \%$, respectively, $P<0.05$, but no significant change in $\beta$-catenin was found in subjects consuming GTE. There were no significant effects observed for any of the three interventions on c-Myc and cyclin D1 mRNA expressions comparing baseline with completion of intervention. There was no interaction between Brazil nuts and GTE, and the effects of the combination of Brazil nuts and GTE on gene expression were not significantly different compared with each intervention given alone.

\section{Effect of intervention on histone acetylation and cell proliferation}

Rectal Ac-H3 was not affected by any intervention. There was no significant effect of any intervention on cell proliferation, although all three interventions showed a trend towards reduced cell proliferation (Fig. 3).

\section{Discussion}

In this study, we tested the potential effects of supplementation of Brazil nuts and GTE alone or in combination on genetic and epigenetic biomarkers related to CRC development in human subjects ( $>50$ years of age). The results show that a 6 -week intervention with Brazil nuts or GTE alone affected gene expressions associated with selenoproteins, WNT signalling, inflammation and DNA methylation. However, the combination of Brazil nuts and GTE did not appear to have any additional effect compared with either of these agents alone. Our findings indicate that supplementation of Se or green tea may play a role in reducing the risk for CRC through regulation of these biomarkers, but that there were no obvious synergistic interactions.

In total, thirty-two of sixty-one subjects - that is, $53 \%$ considered for the study had plasma Se levels $\leq 1.36 \mu \mathrm{mol} / \mathrm{l}$. Therefore, this population might be at increased risk of developing a number of chronic diseases, including $\mathrm{CRC}^{(22)}$ and could benefit from increasing Se intake. It is interesting that six Brazil nuts (providing approximately $48 \mu \mathrm{g} \mathrm{Se} / \mathrm{d}$ ) significantly increased plasma Se levels, confirming it is a good food source of $\mathrm{Se}^{(24)}$. Se, through the selenoproteins, plays a key role in the ability of intestinal epithelial cells to respond to microbial and oxidative challenges; a combination of modest Se deficiency and SNP in selenoprotein genes can impair the protective role in the gastrointestinal tract ${ }^{(34)}$. SePP, the major plasma selenoprotein, is a useful biomarker of Se status ${ }^{(35)}$. Genetic variants of $\mathrm{SePP}^{(36)}$ or decreased SePP mRNA have been reported in CRC patients ${ }^{(37)}$. We previously showed that $150 \mu \mathrm{g} / \mathrm{d}$ Se from Se-enriched milk protein or Se-enriched yeast significantly increased rectal SePP gene expression ${ }^{(29)}$. It has been reported that $75 \mu \mathrm{g} \mathrm{Se} / \mathrm{d}$ is required for full expression of SePP and other plasma Se biomarkers ${ }^{(38)}$. We, however, found that as little as $48 \mu \mathrm{g} / \mathrm{d}$ Se from Brazil nuts was sufficient to raise rectal SePP mRNA, suggesting that Brazil nuts are as effective as other Se supplements.

Se has a wide range of pleiotropic effects, ranging from antioxidant and anti-inflammatory effects to enhancing the production of active thyroid hormone. However, increasing Se intake is complicated because a number of recent clinical trials have indicated that supplementation of people who already have adequate intake with additional se might increase their risk of type 2 diabetes ${ }^{(39)}$. Our data showed that supplementation of six Brazil nuts to individuals with plasma Se level $\leq 1.36 \mu \mathrm{mol} / 1$ did not affect plasma glucose levels, indicating that increasing Se intake in people with low Se status is unlikely to increase the risk of type 2 diabetes. Se-containing enzymes can influence thyroid hormone metabolism, and Se regulates immune response. We did not observe significant effects of Se on thyroid-stimulating hormone, T3 and T4. Moreover, there 
Table 3. Se status and blood clinical chemistry at baseline ('0 weeks') and after intervention (' 6 weeks')

(Mean values and standard deviations for values before and after treatment; mean values with their standard errors, within group change after treatment and between group difference in change in mean are derived from mixed effect models; mean change and $95 \%$ confidence intervals)

\begin{tabular}{|c|c|c|c|c|c|c|c|c|c|c|c|c|}
\hline & & & & & & & \multicolumn{6}{|c|}{ Between group difference } \\
\hline & \multicolumn{2}{|c|}{ Brazil nuts (Se) } & \multicolumn{2}{|c|}{ GTE } & \multicolumn{2}{|c|}{$\mathrm{Se}+\mathrm{GTE}$} & \multicolumn{2}{|c|}{ GTE $v . \mathrm{Se}$} & \multicolumn{2}{|c|}{$\mathrm{Se}+\mathrm{GTE} v$. Se } & \multicolumn{2}{|c|}{$\mathrm{Se}+\mathrm{GTE} v$. GTE } \\
\hline & Mean & SD/SEM & Mean & SD/SEM & Mean & SD/SEM & Mean change & $95 \% \mathrm{Cl}$ & Mean change & $95 \% \mathrm{Cl}$ & Mean change & $95 \% \mathrm{Cl}$ \\
\hline \multicolumn{13}{|l|}{$\mathrm{Se}(\mu \mathrm{mol} / \mathrm{l})$} \\
\hline 0 weeks (SD) & 1.29 & 0.14 & $1 \cdot 20$ & 0.27 & 1.35 & 0.15 & & & & & & \\
\hline 6 weeks (SD) & 1.58 & 0.18 & 1.25 & 0.19 & 1.61 & 0.26 & & & & & & \\
\hline $\begin{array}{l}0 \text { weeks } v \text {. } \\
6 \text { weeks (SEM) }\end{array}$ & 0.28 & 0.05 & 0.05 & 0.06 & 0.26 & 0.08 & -0.23 & $-0.46,-0.01$ & -0.02 & $-0 \cdot 24,0 \cdot 19$ & 0.21 & $0.00,0.42$ \\
\hline$P$ & \multicolumn{2}{|c|}{$<0.001^{*}$} & \multicolumn{2}{|c|}{0.42} & \multicolumn{2}{|c|}{$0.002^{*}$} & \multicolumn{2}{|c|}{$0.04^{\star}$} & \multicolumn{2}{|c|}{0.84} & \multicolumn{2}{|c|}{$0.046^{*}$} \\
\hline Glucose (mmol/l) & & & & & & & & & & & & \\
\hline 0 weeks (sD) & $4 \cdot 8$ & 1.0 & 4.6 & 0.7 & 4.6 & $0 \cdot 8$ & & & & & & \\
\hline 6 weeks (SD) & 4.8 & 0.5 & 4.8 & 0.7 & 4.7 & 0.6 & & & & & & \\
\hline $\begin{array}{l}0 \text { weeks } v \text {. } \\
6 \text { weeks (SEM) }\end{array}$ & 0.01 & 0.24 & $0 \cdot 17$ & $0 \cdot 10$ & $0 \cdot 11$ & 0.22 & 0.16 & $-0.47,0.79$ & $0 \cdot 10$ & $-0.51,0.71$ & -0.06 & $-0.66,0.53$ \\
\hline$P$ & \multicolumn{2}{|c|}{0.96} & \multicolumn{2}{|c|}{$0 \cdot 10$} & \multirow{2}{*}{\multicolumn{2}{|c|}{0.62}} & \multicolumn{2}{|c|}{0.62} & \multicolumn{2}{|c|}{0.75} & \multicolumn{2}{|c|}{0.84} \\
\hline CRP (mg/l) & & & & & & & & & & & & \\
\hline 0 weeks (SD) & 1.7 & 0.7 & $1 \cdot 3$ & $1 \cdot 1$ & 1.9 & 1.7 & & & & & & \\
\hline 6 weeks (SD) & $2 \cdot 0$ & $1 \cdot 1$ & 1.4 & $1 \cdot 0$ & 1.9 & 1.9 & & & & & & \\
\hline $\begin{array}{l}0 \text { weeks } v \text {. } \\
6 \text { weeks (SEM) }\end{array}$ & 0.34 & 0.36 & $0 \cdot 12$ & $0 \cdot 13$ & -0.03 & 0.36 & -0.22 & $-1 \cdot 09,0 \cdot 66$ & -0.37 & $-1 \cdot 22,0.48$ & -0.15 & $-0.98,0.67$ \\
\hline$P$ & \multirow{2}{*}{\multicolumn{2}{|c|}{0.36}} & \multirow{2}{*}{\multicolumn{2}{|c|}{0.33}} & & & & & & & & \\
\hline $\ln (\mathrm{CRP})$ & & & & & & & & & & & & \\
\hline 0 weeks (SD) & 0.42 & 0.51 & -0.12 & 0.94 & 0.21 & 1.04 & & & & & & \\
\hline 6 weeks (SD) & 0.54 & 0.62 & 0.09 & 0.77 & 0.19 & 1.00 & & & & & & \\
\hline $\begin{array}{l}0 \text { weeks } v \text {. } \\
6 \text { weeks (SEM) }\end{array}$ & 0.13 & 0.20 & 0.21 & $0 \cdot 12$ & -0.02 & $0 \cdot 13$ & 0.08 & $-0.34,0.50$ & -0.15 & $-0.56,0.26$ & -0.23 & $-0.63,0.17$ \\
\hline$P$ & & & & & & & & & & & & \\
\hline Creatinine $(\mu \mathrm{mol} / \mathrm{l})$ & & & & & & & & & & & & \\
\hline 0 weeks $(\mathrm{SD})$ & $73 \cdot 8$ & $16 \cdot 2$ & 73.0 & $15 \cdot 3$ & $70 \cdot 3$ & $12 \cdot 3$ & & & & & & \\
\hline 6 weeks (SD) & 73.6 & $13 \cdot 6$ & $74 \cdot 1$ & $13 \cdot 8$ & 65.9 & 13.9 & & & & & & \\
\hline $\begin{array}{l}0 \text { weeks } v \text {. } \\
6 \text { weeks (SEM) }\end{array}$ & -0.22 & $1 \cdot 16$ & $1 \cdot 10$ & $1 \cdot 31$ & -4.45 & $2 \cdot 13$ & $1 \cdot 32$ & $-3.41,6.05$ & $-4 \cdot 23$ & $-8 \cdot 86,0.39$ & $-5 \cdot 55$ & $-10.05,-1.06$ \\
\hline$P$ & & & & & & & & & & & & \\
\hline Urea (mmol/l) & & & & & & & & & & & & \\
\hline 0 weeks (SD) & $6 \cdot 0$ & 1.5 & $6 \cdot 6$ & $2 \cdot 3$ & 5.9 & 1.4 & & & & & & \\
\hline 6 weeks (SD) & 6.6 & 1.4 & $6 \cdot 6$ & $2 \cdot 3$ & $5 \cdot 6$ & 1.4 & & & & & & \\
\hline $\begin{array}{l}0 \text { weeks } v \text {. } \\
6 \text { weeks (SEM) }\end{array}$ & 0.66 & 0.22 & -0.05 & 0.31 & -0.25 & 0.27 & -0.71 & $-1.49,0.07$ & -0.90 & $-1 \cdot 66,-0.14$ & -0.20 & $-0.94,0.55$ \\
\hline$P$ & & & & & & & & & & & & \\
\hline TSH (pmol/l) & & & & & & & & & & & & \\
\hline 0 weeks (SD) & 1.95 & 1.22 & $2 \cdot 36$ & 1.07 & 1.58 & 0.77 & & & & & & \\
\hline 6 weeks $(\mathrm{SD})$ & 1.96 & 1.51 & 2.64 & $1 \cdot 11$ & 1.41 & 0.63 & & & & & & \\
\hline $\begin{array}{l}0 \text { weeks } v \text {. } \\
6 \text { weeks (SEM) }\end{array}$ & 0.01 & 0.26 & 0.28 & 0.18 & -0.13 & 0.13 & 0.27 & $-0.27,0.82$ & -0.12 & $-0.67,0.42$ & -0.40 & $-0.93,0.13$ \\
\hline$P$ & & & & & & & & & & & & \\
\hline T3 (mmol/l) & & & & & & & & & & & & \\
\hline 0 weeks $(\mathrm{SD})$ & $5 \cdot 0$ & 0.6 & 4.9 & 0.5 & $5 \cdot 2$ & 0.9 & & & & & & \\
\hline 6 weeks (SD) & 4.9 & 0.5 & 4.9 & 0.8 & 4.8 & 0.6 & & & & & & \\
\hline
\end{tabular}


were no adverse changes in blood markers related to liver or renal function (any changes remained within the normal range). Therefore, Se supplementation from Brazil nuts appears to be a safe and cost-effective way to increase Se levels, specifically in subjects at the lower side of normal Se status.

The aberrant activation of the WNT signalling pathway and subsequent $\beta$-catenin/Tcf-lymphoid enhancer factor complex formation are key elements involved in colonic carcinogenesis. Se deficiency does not only reduce synthesis of selenoproteins but also affects the expression of signalling pathways associated with carcinogenesis. Animal studies have shown that moderate Se deficiency can activate the WNT pathway ${ }^{(40,41)}$ and promote inflammatory neoplastic transformation ${ }^{(42)}$. WNT, therefore, has been considered as a promising target for cancer prevention and treatment ${ }^{(43-45)}$. In the current study, we found that supplementation of Brazil nuts alone or in combination with GTE significantly reduced rectal $\beta$-catenin gene expression, although no significant changes in two of the $\beta$-catenin target genes (c-Myc and cyclin D1) were observed. Although GTE alone had no effect on WNT signalling, GTE has been reported to inhibit the WNT/ $\beta$-catenin pathway in vitro by promoting GSK- $3 \beta$ - and PP2A-independent $\beta$-catenin phosphorylation/degradation ${ }^{(46)}$. These are the first data from humans to suggest that Se affects $\beta$-catenin expression, which is consistent with the data from our previous study in the CRC rat model ${ }^{(29)}$.

Activation of inflammation biomarkers NF- $\kappa \mathrm{B}$ is linked to multiple aspects of oncogenesis, including the control of apoptosis, cell cycle, differentiation, angiogenesis and cell migration. Brazil nut consumption is reported to decrease inflammatory biomarkers of IL-1, IL-6, TNF- $\alpha$ and interferon- $\gamma$ in blood samples of healthy volunteers ${ }^{(47)}$. Synthetic organoselenium $^{(48)}$ or EGCG ${ }^{(49)}$ can inhibit COX-2, NF- $\kappa \mathrm{B}$ and $\beta$-catenin in colon cancer cells. We found that GTE alone or in combination with Brazil nuts significantly reduced NF- $\kappa$ B mRNA expression. In a recent study, 113 men diagnosed with prostate cancer were randomised to consume six cups of brewed GTE, black tea extract or water before radical prostatectomy. The results showed that NF- $\kappa \mathrm{B}$ was significantly decreased only in men consuming GTE. Moreover, thirty-two of thirty-four men taking GTE had EGCG detected in prostate tissue ${ }^{(50)}$. Although we did not observe a significant effect of Se on inflammation, the anti-inflammatory property of GTE appears to be consistent.

Epigenetic mechanisms play a pivotal role in gene expression; EGCG from green tea can affect various epigenetic mechanisms such as DNMT inhibition and histone modifications via histone deacetylase (HDAC) ${ }^{(51,52)}$. Naturally occurring organoselenium compounds can also act as HDAC inhibitors because they share structural features with the HDAC inhibitor of butyrate (a SCFA) ${ }^{(53)}$. Consistent with previous in vitro and in vivo studies, we found that GTE alone or in combination significantly reduced the expression of DNMT1 mRNA. EGCG can reactivate methylation-silenced tumour suppressor genes in cancer cell lines ${ }^{(49)}$ by inhibiting DNMT1 ${ }^{(54)}$. This is the first study to show that GTE can modulate DNMT1 mRNA in human subjects. As GTE has an acceptable safety profile, further research on its action as an inhibitor of DNA methylation is warranted. In contrast to the finding from our previous animal study, we did not find Brazil nuts or the combination to affect 
(a)

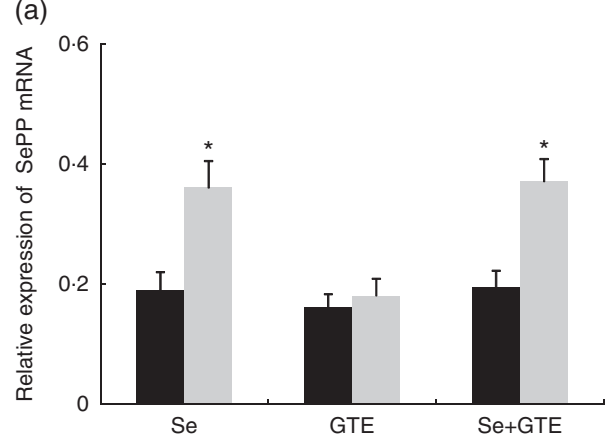

(c)

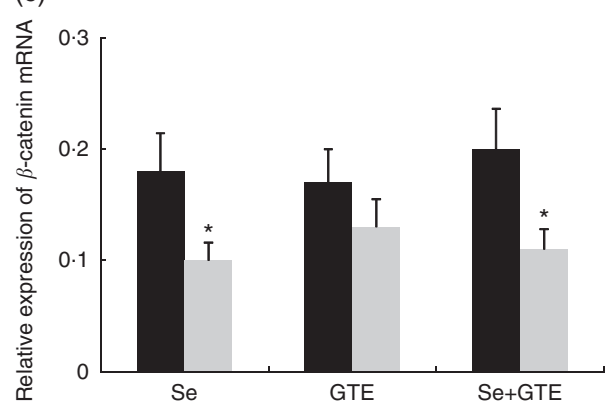

(e)

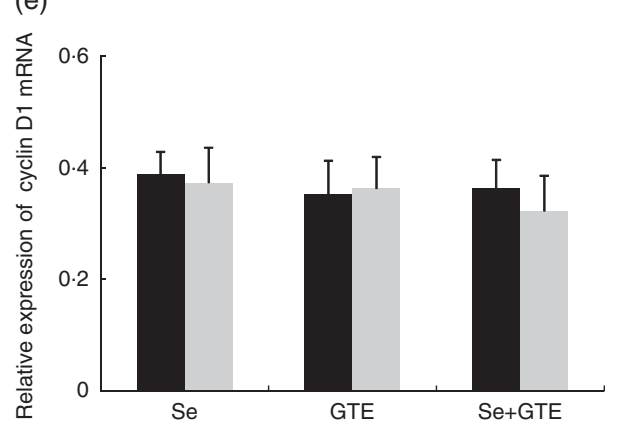

(b)

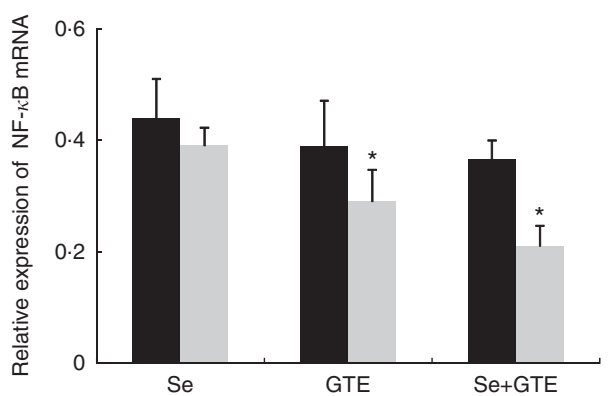

(d)

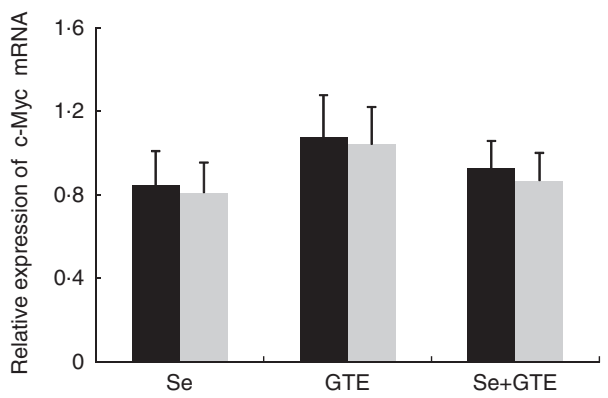

(f)

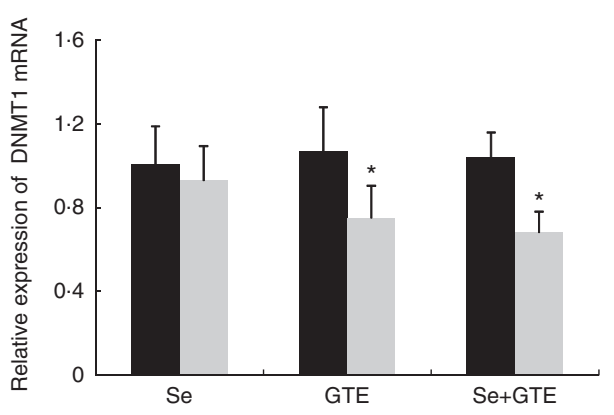

Fig. 2. Effects of supplementation of Brazil nuts (selenium), green tea extract (GTE) and the combination of Brazil nuts and GTE on rectal selenoprotein $P$ (SePP) (a), NF- $k B(b), \beta$-catenin (c), c-Myc (d), cyclin D1 (e) and DNA methyltransferase 1 (DNMT1) (f) mRNA expressions. Values are means with their standard errors represented by vertical bars. ${ }^{*} P<0.05$. $\square$, Before; $\square$, after.

rectal Ac-H3 expression, although reduced staining of Ac-H3 was observed in colon tumours, compared with rectal biopsies (unpublished data). Previous studies have suggested that 4-6 weeks of dietary intervention proved adequate to induce changes in biomarkers or stabilise epithelial kinetics ${ }^{(29)}$. It is yet to be tested whether a longer intervention of Brazil nuts is required to see changes in $\mathrm{AC}-\mathrm{H} 3$ protein expression.

The strategy of combining chemopreventive agents at low doses or combining dietary agents is being increasingly investigated. Brazil nuts and GTE appear to exert their protective effects via different mechanisms. However, contrary to our hypothesis and the results of our previous animal study ${ }^{(17)}$, the effect of the combination of Se and GTE on all measured biomarkers was not greater than that of either Se or GTE alone. There are several explanations for the gap between preclinical and clinical research. First, the main end point of the animal study was tumour outcome; second, the animal study was a long-term study; third, the forms and doses of Se and GTE used in this human intervention were different to that used in the animal studies; and, finally, there might be species differences in the way these genes are regulated by Se or GTE. Factors such as host genetic susceptibility, epigenetic modification and gut microbiota profile might also play roles in the potential effect of the combination of Se and GTE. Furthermore, findings from animal studies are not always replicated in human trials, and this combination is not as promising as that predicted from animal studies.

The strengths of this study include the following: (1) to our knowledge, this is the first randomised clinical trial to test the effects of supplementation with Brazil nuts and GTE, alone and in combination, on biomarkers related to risk for CRC in human subjects; (2) adherence to the intervention was very good with confirmation of compliance with Brazil nut consumption from the rise in Se levels; (3) no side-effects were seen; (4) the intervention is feasible; and (5) we linked the intervention to perceived mechanisms of action of these agents. 
(a)

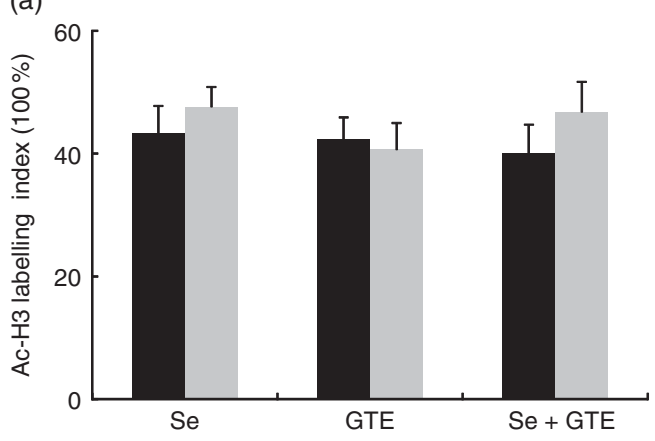

(c)

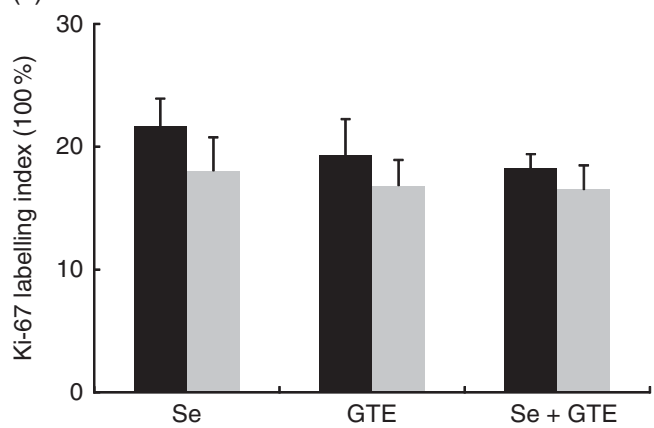

(b)

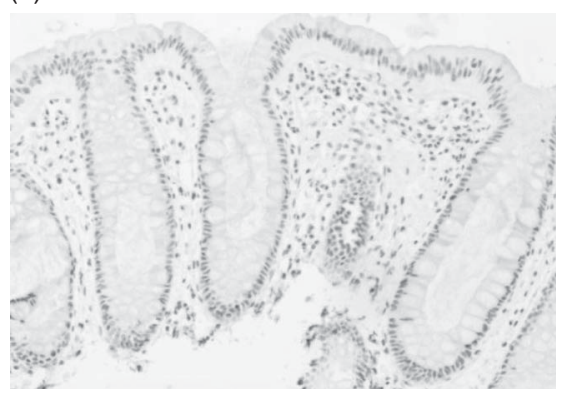

(d)

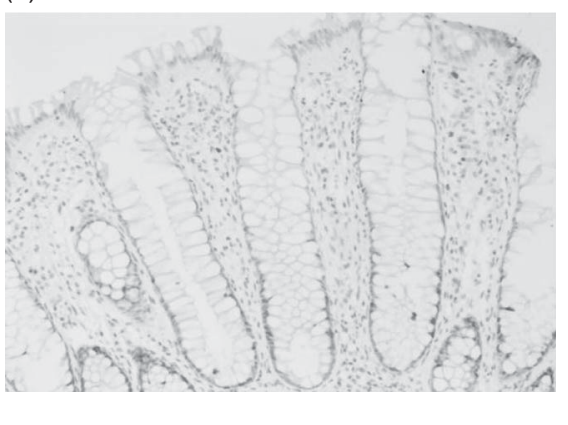

Fig. 3. Effects of supplementation of Brazil nuts (selenium), green tea extract (GTE) and the combination of Brazil nuts and GTE on acetylated histone $\mathrm{H} 3$ (Ac-H3) (a) and Ki-67 expression (c). Representative sections of immunohistochemical staining for Ac-H3 (b) and Ki-67 (d) in the rectal epithelial cells show typical nuclear staining. Values are means with their standard errors. $\square$, Before; $\square$, after.

Our study had several potential limitations: (1) we were unable to examine the EGCG levels in blood and assess the bioavailability of EGCG in the target organ of rectal biopsies; (2) because of the limitation of biopsy samples, we only measured gene expression of selenoproteins, WNT signalling pathway, inflammation and methylation, and could not, therefore, correlate changes in gene expression with changes in protein expression; (3) we did not control total dietary intake of Se or EGCG but tested the interventions in a pragmatic sense without artificial manipulation of the diet; and (4) lack of measurement of large-scale gene expression, and thus the potential effects of Brazil nuts and GTE alone or in combination on other gene expressions, particularly other $\beta$-catenin target genes, are unknown.

This is the first study to examine the potential effects of Brazil nuts and GTE alone or in combination on biomarkers related to risk for CRC. Our results suggest that supplementation of Brazil nuts or GTE might reduce risk for CRC by regulating genes associated with selenoproteins (SePP), WNT signalling $(\beta$-catenin), inflammation (NF- $\kappa \mathrm{B})$ and methylation (DNMT1), but the combination did not have additional effects on these biomarkers. These findings, combined with the excellent safety profile of the interventions and the very low cost, should encourage further investigations on these agents as potential chemopreventive agents for CRC.

\section{Acknowledgements}

The authors thank the volunteers who took part in this study, and also thank Dr Leonid Ber and Now Foods, USA, for providing GTE capsules and for their support.
This study was supported by the National Health and Medical Research Council of Australia (project grant no. 1007501) and Cancer Council of South Australia.

The authors' responsibilities were as follows: Y. H., G. P. Y., G. H. M. and R. K. L. L. designed and conducted the study; X. Q. M. performed statistical analyses; Y. H., R. K. L. L. and R. S. performed measurements and analysis; G. G. and L. B. coordinated the volunteers and collected samples; Y. H., G. P. Y., G. H. M., R. K. L. L. and R. A. M. interpreted the results and wrote the manuscript; all the authors read and approved the final manuscript.

The authors declare that there are no conflicts of interest.

\section{References}

1. Rothwell PM, Wilson M, Elwin CE, et al. (2010) Long-term effect of aspirin on colorectal cancer incidence and mortality: 20-year follow-up of five randomised trials. Lancet $\mathbf{3 7 6}$, 1741-1750.

2. Sutcliffe P, Connock M, Gurung T, et al. (2013) Aspirin in primary prevention of cardiovascular disease and cancer: a systematic review of the balance of evidence from reviews of randomized trials. PLOS ONE 8, e81970.

3. Holt PR, Atillasoy EO, Gilman J, et al. (1998) Modulation of abnormal colonic epithelial cell proliferation and differentiation by low-fat dairy foods: a randomized controlled trial. JAMA 280, 1074-1079.

4. Yang CS, Wang X, Lu G, et al. (2009) Cancer prevention by tea: animal studies, molecular mechanisms and human relevance. Nat Rev Cancer 9, 429-439.

5. Nolfo F, Rametta S, Marventano S, et al. (2013) Pharmacological and dietary prevention for colorectal cancer. BMC Surg 13, S16. 
6. Henning SM, Wang P, Abgaryan N, et al. (2013) Phenolic acid concentrations in plasma and urine from men consuming green or black tea and potential chemopreventive properties for colon cancer. Mol Nutr Food Res 57, 483-493.

7. Clark LC, Combs GF Jr., Turnbull BW, et al. (1996) Effects of selenium supplementation for cancer prevention in patients with carcinoma of the skin. A randomized controlled trial. Nutritional Prevention of Cancer Study Group. JAMA 276, 1957-1963.

8. Yuan JM, Gao YT, Yang CS, et al. (2007) Urinary biomarkers of tea polyphenols and risk of colorectal cancer in the Shanghai Cohort Study. Int J Cancer 120, 1344-1350.

9. Yang CS, Chen JX, Wang H, et al. (2016) Lessons learned from cancer prevention studies with nutrients and non-nutritive dietary constituents. Mol Nutr Food Res 60, 1239-1250.

10. Peters U, Chatterjee N, Church TR, et al. (2006) High serum selenium and reduced risk of advanced colorectal adenoma in a colorectal cancer early detection program. Cancer Epidemiol Biomarkers Prev 15, 315-320.

11. Lippman SM, Klein EA, Goodman PJ, et al. (2009) Effect of selenium and vitamin $\mathrm{E}$ on risk of prostate cancer and other cancers: the Selenium and Vitamin E Cancer Prevention Trial (SELECT). JAMA 301, 39-51.

12. Fujiki H, Sueoka E, Watanabe T, et al. (2015) Primary cancer prevention by green tea, and tertiary cancer prevention by the combination of green tea catechins and anticancer compounds. J Cancer Prev 20, 1-4.

13. Yang CS, Li G, Yang Z, et al. (2013) Cancer prevention by tocopherols and tea polyphenols. Cancer Lett 334, 79-85.

14. Christensen MJ (2014) Selenium and prostate cancer prevention: what next - if anything? Cancer Prev Res (Phila) 7, 781-785.

15. Gaziano JM, Sesso HD, Christen WG, et al. (2012) Multivitamins in the prevention of cancer in men: the Physicians' Health Study II randomized controlled trial. JAMA $\mathbf{3 0 8}$, 1871-1880.

16. Fujiki H, Sueoka E, Watanabe T, et al. (2015) Synergistic enhancement of anticancer effects on numerous human cancer cell lines treated with the combination of EGCG, other green tea catechins, and anticancer compounds. J Cancer Res Clin Oncol 141, 1511-1522.

17. Hu Y, McIntosh GH, Le Leu RK, et al. (2013) Combination of selenium and green tea improves the efficacy of chemoprevention in a rat colorectal cancer model by modulating genetic and epigenetic biomarkers. PLOS ONE 8, e64362.

18. Khan N, Afaq F, Saleem M, et al. (2006) Targeting multiple signaling pathways by green tea polyphenol (-)-epigallocatechin3-gallate. Cancer Res 66, 2500-2505.

19. Meplan C, Johnson IT, Polley AC, et al. (2016) Transcriptomics and proteomics show that selenium affects inflammation, cytoskeleton, and cancer pathways in human rectal biopsies. FASEB J 30, 2812-2825.

20. Maresso KC, Tsai KY, Brown PH, et al. (2015) Molecular cancer prevention: current status and future directions. CA Cancer J Clin 65, 345-383.

21. Lymbury R, Tinggi U, Griffiths L, et al. (2008) Selenium status of the Australian population: effect of age, gender and cardiovascular disease. Biol Trace Elem Res 126, S1-S10.

22. Hughes DJ, Fedirko V, Jenab M, et al. (2015) Selenium status is associated with colorectal cancer risk in the European prospective investigation of cancer and nutrition cohort. Int J Cancer 136, 1149-1161.

23. Duffield-Lillico AJ, Reid ME, Turnbull BW, et al. (2002) Baseline characteristics and the effect of selenium supplementation on cancer incidence in a randomized clinical trial: a summary report of the Nutritional Prevention of Cancer Trial. Cancer Epidemiol Biomarkers Prev 11, 630-639.
24. Thomson CD, Chisholm A, McLachlan SK, et al. (2008) Brazil nuts: an effective way to improve selenium status. Am J Clin Nutr 87, 379-384.

25. Chow HH, Cai Y, Hakim IA, et al. (2003) Pharmacokinetics and safety of green tea polyphenols after multiple-dose administration of epigallocatechin gallate and polyphenon $\mathrm{E}$ in healthy individuals. Clin Cancer Res 9, 3312-3319.

26. Shanafelt TD, Call TG, Zent CS, et al. (2009) Phase I trial of daily oral Polyphenon E in patients with asymptomatic Rai stage 0 to II chronic lymphocytic leukemia. J Clin Oncol 27, 3808-3814.

27. Crew KD, Brown P, Greenlee H, et al. (2012) Phase IB randomized, double-blinded, placebo-controlled, dose escalation study of polyphenon $\mathrm{E}$ in women with hormone receptornegative breast cancer. Cancer Prev Res (Phila) 5, 1144-1154.

28. Hu Y, McIntosh GH, Le Leu RK, et al. (2010) Seleniumenriched milk proteins and selenium yeast affect selenoprotein activity and expression differently in mouse colon. Br J Nutr 104, 17-23.

29. Hu Y, McIntosh GH, Le Leu RK, et al. (2011) The influence of selenium-enriched milk proteins and selenium yeast on plasma selenium levels and rectal selenoprotein gene expression in human subjects. Br J Nutr 106, 572-582.

30. Simon P (2003) Q-Gene: processing quantitative real-time RT-PCR data. Bioinformatics 19, 1439-1440.

31. Hu Y, McIntosh GH, Le Leu RK, et al. (2008) Suppression of colorectal oncogenesis by selenium-enriched milk proteins: apoptosis and K-ras mutations. Cancer Res 68, 4936-4944.

32. Puntoni M, Branchi D, Argusti A, et al. (2013) A randomized, placebo-controlled, preoperative trial of allopurinol in subjects with colorectal adenoma. Cancer Prev Res (Phila) 6, 74-81.

33. Hosono K, Endo H, Takahashi H, et al. (2010) Metformin suppresses colorectal aberrant crypt foci in a short-term clinical trial. Cancer Prev Res (Phila) 3, 1077-1083.

34. Meplan C \& Hesketh J (2012) The influence of selenium and selenoprotein gene variants on colorectal cancer risk. Mutagenesis 27, 177-186.

35. Combs GF Jr. (2015) Biomarkers of selenium status. Nutrients 7, 2209-2236.

36. Peters U, Chatterjee N, Hayes RB, et al. (2008) Variation in the selenoenzyme genes and risk of advanced distal colorectal adenoma. Cancer Epidemiol Biomarkers Prev 17, $1144-1154$.

37. Speckmann B, Pinto A, Winter M, et al. (2010) Proinflammatory cytokines down-regulate intestinal selenoprotein P biosynthesis via NOS2 induction. Free Radic Biol Med 49, 777-785.

38. Xia Y, Hill KE, Li P, et al. (2010) Optimization of selenoprotein $\mathrm{P}$ and other plasma selenium biomarkers for the assessment of the selenium nutritional requirement: a placebo-controlled, double-blind study of selenomethionine supplementation in selenium-deficient Chinese subjects. Am J Clin Nutr 92, 525-531.

39. Rayman MP (2012) Selenium and human health. Lancet 379, 1256-1268.

40. Kipp A, Banning A, van Schothorst EM, et al. (2009) Four selenoproteins, protein biosynthesis, and Wnt signalling are particularly sensitive to limited selenium intake in mouse colon. Mol Nutr Food Res 53, 1561-1572.

41. Brigelius-Flohe R \& Kipp AP (2013) Selenium in the redox regulation of the Nrf2 and the Wnt pathway. Methods Enzymol 527, 65-86.

42. Barrett CW, Singh K, Motley AK, et al. (2013) Dietary selenium deficiency exacerbates DSS-induced epithelial injury and AOM/DSS-induced tumorigenesis. PLOS ONE 8, e67845. 
43. Teiten MH, Gaascht F, Dicato M, et al. (2012) Targeting the wingless signaling pathway with natural compounds as chemopreventive or chemotherapeutic agents. Curr Pharm Biotechnol 13, 245-254.

44. Kipp AP, Muller MF, Goken EM, et al. (2012) The selenoproteins GPx2, TrxR2 and TrxR3 are regulated by Wnt signalling in the intestinal epithelium. Biochim Biophys Acta 1820, 1588-1596.

45. Wang LS, Kuo CT, Cho SJ, et al. (2013) Black raspberryderived anthocyanins demethylate tumor suppressor genes through the inhibition of DNMT1 and DNMT3B in colon cancer cells. Nutr Cancer 65, 118-125.

46. Oh S, Gwak J, Park S, et al. (2014) Green tea polyphenol EGCG suppresses Wnt/beta-catenin signaling by promoting GSK-3beta- and PP2A-independent beta-catenin phosphorylation/degradation. Biofactors 40, 586-595.

47. Colpo E, Dalton DAVC, Reetz LG, et al. (2014) Brazilian nut consumption by healthy volunteers improves inflammatory parameters. Nutrition 30, 459-465.

48. Narayanan BA, Narayanan NK, Desai D, et al. (2004) Effects of a combination of docosahexaenoic acid and 1,4-phenylene bis(methylene) selenocyanate on cyclooxygenase 2 , inducible nitric oxide synthase and beta-catenin pathways in colon cancer cells. Carcinogenesis 25, 2443-2449.

49. Yiannakopoulou EC (2015) Targeting DNA methylation with green tea catechins. Pharmacology 95, 111-116.

50. Henning SM, Wang P, Said JW, et al. (2015) Randomized clinical trial of brewed green and black tea in men with prostate cancer prior to prostatectomy. Prostate 75, 550-559.

51. Daniel M \& Tollefsbol TO (2015) Epigenetic linkage of aging, cancer and nutrition. J Exp Biol 218, 59-70.

52. Speckmann B \& Grune $T$ (2015) Epigenetic effects of selenium and their implications for health. Epigenetics 10, 179-190.

53. Lee JI, Nian H, Cooper AJ, et al. (2009) Alpha-keto acid metabolites of naturally occurring organoselenium compounds as inhibitors of histone deacetylase in human prostate cancer cells. Cancer Prev Res (Phila) 2, 683-693.

54. Fang MZ, Wang Y, Ai N, et al. (2003) Tea polyphenol (-)-epigallocatechin-3-gallate inhibits DNA methyltransferase and reactivates methylation-silenced genes in cancer cell lines. Cancer Res 63, 7563-7570. 